\title{
Optimization of steam distillation for extracting cinnamomum cassia oil from cinnamomum cassia bark
}

\author{
Jianlong Li 1, a, Fengrui Sun 2, b, Weiwen Wang ${ }^{3, ~ c}$, Fei Gao ${ }^{4, d^{*}}$ \\ ${ }^{1}$ Institute of Chemical Engineering, Qingdao University of Science and Technology, Qingdao 266042, \\ China \\ ${ }^{2}$ Institute of Chemical Engineering, Qingdao University of Science and Technology, Qingdao 266042, \\ China \\ ${ }^{3}$ Institute of Chemical Engineering, Qingdao University of Science and Technology, Qingdao 266042, \\ China \\ ${ }^{4}$ Institute of Chemical Engineering, Qingdao University of Science and Technology, Qingdao 266042, \\ China
}

aljlong@qust.edu.cn, bsfrui1128@163.com, ‘wwwang@qust.edu.cn, dfeigao@qust.edu.cn

Keywords: Steam distillation; Cinnamomum cassia oil; Orthogonal test; Cinnamomum cassia bark

\begin{abstract}
The aim of this work was to optimize the distillation conditions for extracting cinnamomum cassia oil from cinnamomum cassia bark by steam distillation. The orthogonal test was conducted to investigate the effects of the three main factors on cinnamomum cassia oil yield, including the solid-liquid ratio, the distillation time and the fragmentation degree of cinnamomum cassia bark. The investigation results show that the influence of the distillation conditions on extraction performance follows the sequence: fragmentation degree of cinnamomum cassia bark, the solid-liquid ratio and distillation time. And the optimum conditions are the fragmentation degree of $40 \mathrm{mesh}$, the ratio of material to liquid of $1 / 10$ and the distillation time of $2 \mathrm{~h}$. At the optimum distillation conditions, the cinnamomum cassia oil yield is about $1.44 \%$, and the extracted cinnamomum cassia oil has good quality with gold yellow color and prominent cinnamon scent.
\end{abstract}

\section{Introduction}

Cinnamon is a member of the Lauraceae family, which is mainly distributed in China, Madagascar, India, Srilanka, Seychelles, Vietnam and Malaysia. The barks, twigs and leaves of cinnamon are the important sources of cinnamomum cassia oils, and the cinnamomum cassia bark has become the main raw material for extracting cinnamomum cassia oils due to its highest content of cinnamomum cassia oil. The main components of cinnamomum cassia oil are benzaldehyde, cinnamaldehyde, phenylpropyl aldehyde, cinnamyl acetate and o-methoxy cinnamicaldehyde. More than half of cinnamomum cassia oil is cinnamaldehyde. Cinnamomum cassia oil displays the good activities of antioxidant, antiallergy, anticancer and antibacterial, and has been observed to apply to treat stomach pain, prevent diabetes, tumor, hypertension and other diseases [1]. In addition, cinnamomum cassia oil has been widely used as the flavouring in the food and cosmetic industries, and as the solvents for cleaning products and manufacturing pesticides.

The traditional methods for extracting cinnamomum cassia oils include distillation, cold pressing and solvent extraction [2]. And the traditional extraction ways have some disadvantages of long extraction time, loss and destruction of components and energy-intensive. Recently, with the increasing demand for cinnamomum cassia oil, some new technologies with higher extraction yield have been developed, such as microwave extraction, ultrasound extraction and supercritical fluid extraction. However, these new technologies are not suitable for extracting cinnamomum cassia oil from cinnamomum cassia bark on a large scale due to the low production capacity and high operations costs [3].

Steam distillation is considered as the most effective technology for extracting cinnamomum cassia oil from cinnamomum cassia bark due to its high production capacity, easy operations and 
small equipment in size [4], which could avoid the shortcoming of traditional extraction ways and satisfy the needs of large-scale production. During the steam distillation process, the water molecules easily diffuse into the plant cells due to the penetration and diffusion of water, and the oil-water azeotrope is formed and released through evaporation. After that the steam and cinnamomum cassia oils vapour are condensed by using a condenser. Finally, the collected liquid mixtures are separated to obtain the cinnamomum cassia oil [5]. Based on the principle of steam distillation, the distillation conditions will have a significant impact on the extraction performance. Thus, in this work, the effects of distillation conditions on extraction performance were investigated to optimize the distillation conditions for extracting cinnamomum cassia oil by steam distillation, including the solid-liquid ratio, distillation time and the fragmentation degree of cinnamomum cassia bark. And the effect of the three main factors on cinnamomum cassia oil yield were systematically investigated by the single factor experiments and the orthogonal experiments [6].

\section{Experimental}

\subsection{Plant and chemical material}

In this work, the used cinnamomum cassia bark was gathered from Luo ding Rong xing Spice Co., Ltd., located in $20 \mathrm{~km}$ west of Luo ding City. Fresh raw materials were used in all extractions. Sodium chloride (AR) and dichloromethane (AR) were provided by Qingdao Zheng ye Reagent Instrument Co, Ltd.

\subsection{Pretreatment}

Prior to the distillation experiment, the fresh cinnamomum cassia bark was cleaned using distilled water for 30 min to eliminate the dirt and small particles on the surface of cinnamomum cassia bark, and then dried at an ambient temperature for $48 \mathrm{~h} \mathrm{[7].} \mathrm{The} \mathrm{moisture} \mathrm{content} \mathrm{of} \mathrm{the} \mathrm{raw} \mathrm{material} \mathrm{is}$ about $35 \%$. After that, the cinnamomum cassia bark was crushed and ground with a household crusher. The pulverized granules will be passed through the screens with different meshes, and the resulting raw materials were collected in groups and dried at $120^{\circ} \mathrm{C}$ for $12 \mathrm{~h}$. Before the extraction, the dried cinnamon powder sample was stored in a desiccator. All values are based on dry weight.

\subsection{Extraction apparatus and procedures}

In order to extract the cinnamomum cassia oil by steam distillation, a steam generator and a $1000 \mathrm{ml}$ three-neck round bottom flask were used to assemble a set of steam distillation apparatus and a 250 $\mathrm{ml}$ Erlenmeyer flask was used as the receiver. The $40 \mathrm{~g}$ with different sizes of cinnamomum cassia barks were put in a $1000 \mathrm{~mL}$ three mouth flask, and then the hot water $\left(50{ }^{\circ} \mathrm{C}\right)$ was added with different solid-liquid ratio. Finally, and the solution was reached to boiling at a stable time rate with different distillation time. the spilled product was collected until it is free of oil. The distillate was taken out in a $250 \mathrm{ml}$ separating funnel and extracted twice with dichloromethane [8]. After the layers were separated, the aqueous layer was discarded. The organic layer was poured from the funnel and placed in a weighed $50 \mathrm{ml}$ distillation flask. The distillation flask was heated with an electric heating jacket and the dichloromethane was distilled off. After cooling, it was weighed. The yield of the cinnamomum cassia oil was calculated based on the raw cinnamomum cassia bark [9].

The yield of cinnamomum cassia oils under different the solid-liquid ratio, distillation time and degree of fragmentation were measured and single factor test and orthogonal test were performed.

The extraction rate of cinnamomum cassia oil can be calculated as follows:

Extraction rate (Yield \%) $=\mathrm{m}_{1} / \mathrm{m}_{2} \times 100 \%$

Where $\mathrm{m}_{1}$ is the quality of cinnamomum cassia oil, and $\mathrm{m}_{2}$ is quality of raw material. 


\section{Results and Discussion}

\subsection{Yield of the cinnamomum cassia oil as Function of degree of fragmentation}

All cinnamomum cassia oils extracted from cinnamomum cassia bark with different degree of fragmentation show a clear, yellow liquid. Fig.1 shows the effect of the fragmentation degree of cinnamomum cassia bark on the cinnamomum cassia oil yield. It can been found that the cinnamomum cassia oil yield increases from $0.554 \%$ to $1.32 \%$ with increasing the fragmentation degree from 20 to 40 mesh, and decreases gradually with further increasing the fragmentation degree. Thus, the optimal fragmentation degree cinnamomum cassia bark is 40 mesh. When the fragmentation degrees are lower than 40 mesh, the lower cinnamomum cassia oil yield may be due to the lower specific surface area of the cinnamomum cassia bark with the bigger particle sizes, restricting the mass transfer[10]. However, when the fragmentation degrees are higher than 40 mesh, the particle size of cinnamomum cassia bark are too small, and raw materials and water will bond together, resulting in that oil can not be separated from the water.
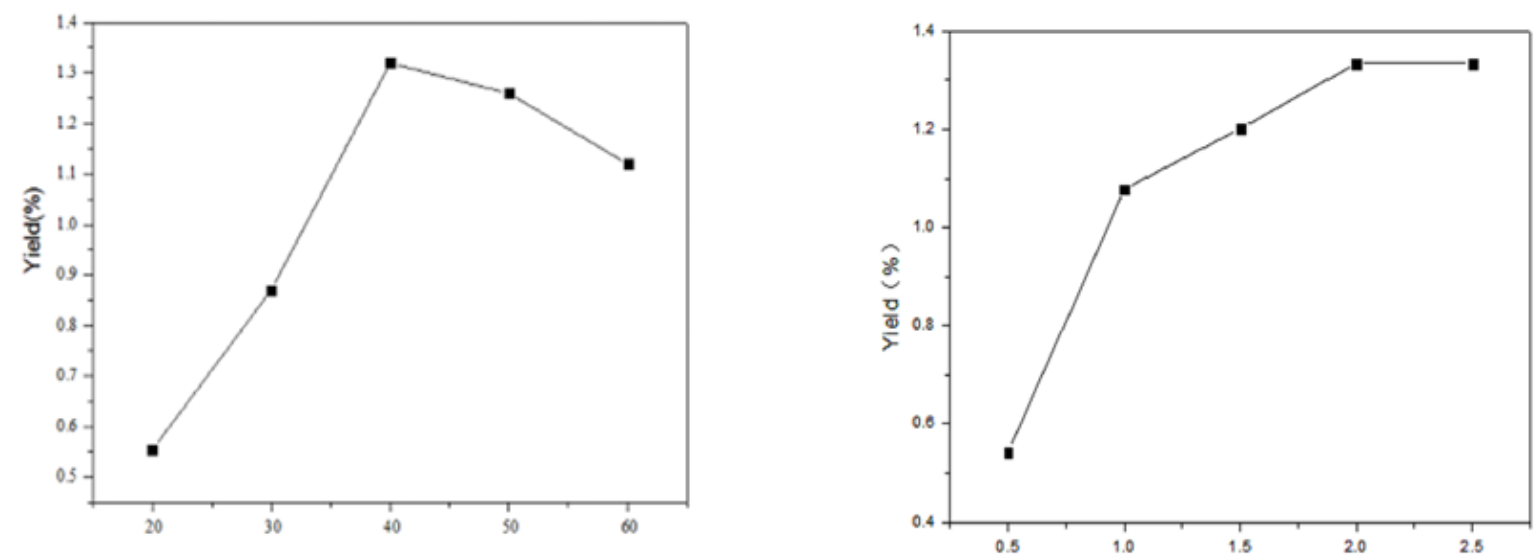

Fig.1 Effect of degree of fragmentation on oil rate Fig.2 Effect of distillation time on oil rate

\subsection{Yield of the cinnamomum cassia oil as Function of distillation time}

The effect of distillation time on the yield of the cinnamomum cassia oil is showed in Fig. 2. When the distillation time increases from 0.5 to $2 \mathrm{~h}$, the yield of the cinnamomum cassia oil increases from $0.524 \%$ to $1.334 \%$. With further increasing the distillation time to $2.5 \mathrm{~h}$, the yield of the cinnamomum cassia oil is almost constant. The result shows that the distillation time is the most suitable for $2 \mathrm{~h}$.

\subsection{Yield of the cinnamomum cassia oil as Function of the solid-liquid ratio}

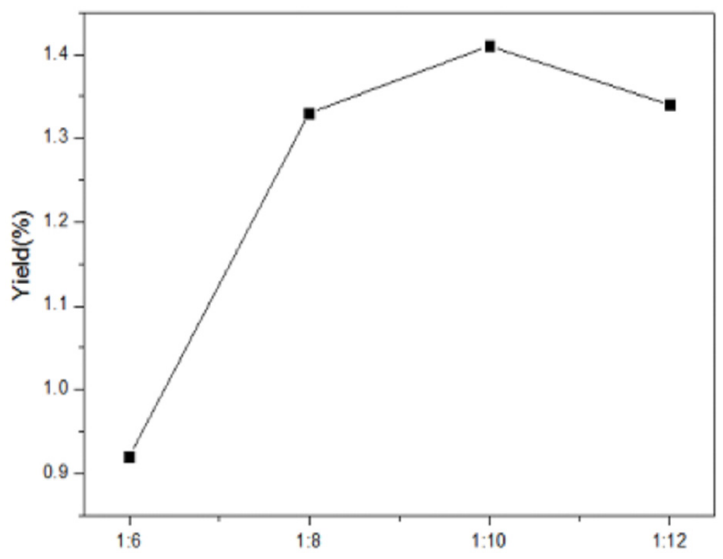

Fig. 3 shows the effect of the solid-liquid ratio on the yield of the cinnamomum cassia oil under the same conditions ( 40 mesh, $2 \mathrm{~h}$ ). It can been found that the cinnamomum cassia oil yield increases 
from $0.92 \%$ to $1.41 \%$ with increasing the solid-liquid ratio from $1 / 6$ to $1 / 10$, and decreases gradually with further increasing the solid-liquid ratio. When the solid-liquid ratio is higher than $1 / 10$, the excessive quantities of water caused bumping, and some raw materials are splashed on the wall of the container, resulting in the loss of raw materials. So, the Fig. 3 Effect of the solid-liquid ratio on oil rate solid-liquid ratio of $1 / 10$ is appropriate.

\subsection{Optimization on the Extraction Technology of Cinnamon by Steam Distillation}

Table 1 Factors and levels of the orthogonal test

\begin{tabular}{cccc}
\hline level & A & B & C \\
\hline $\begin{array}{c}\text { the degree of } \\
\text { fragmentation } \\
(\text { mesh })\end{array}$ & distillation time & the solid-liquid ratio $(\mathrm{w} / \mathrm{w})$ \\
1 & 30 & $(\mathrm{~h})$ & $1 / 8$ \\
2 & 40 & 1.5 & $1 / 9$ \\
3 & 50 & 2 & $1 / 10$ \\
\hline
\end{tabular}

Table 2 Results of the orthogonal test $\mathrm{L}_{9}\left(3^{4}\right)$

\begin{tabular}{clllll}
\hline Test & $\mathrm{A}$ & $\mathrm{B}$ & $\mathrm{C}$ & blank & yield $(\%)$ \\
\hline 1 & 1 & 1 & 1 & 1 & 0.21 \\
2 & 1 & 2 & 2 & 2 & 0.42 \\
3 & 1 & 3 & 3 & 3 & 0.65 \\
4 & 2 & 1 & 2 & 3 & 1.31 \\
5 & 2 & 2 & 3 & 1 & 1.44 \\
6 & 2 & 3 & 1 & 2 & 1.23 \\
7 & 3 & 1 & 3 & 2 & 1.02 \\
8 & 3 & 2 & 1 & 3 & 0.51 \\
9 & 3 & 3 & 2 & 1 & 0.32 \\
$\mathrm{~K}_{1}$ & 1.28 & 2.54 & 1.95 & 1.97 & \\
$\mathrm{~K}_{2}$ & 3.98 & 2.37 & 2.05 & 2.67 & \\
$\mathrm{~K}_{3}$ & 1.85 & 2.2 & 3.11 & 2.47 & \\
$\mathrm{R}$ & 0.9 & 0.11 & 0.38 & 0.23 & \\
\hline
\end{tabular}

As shown in Table 1, the distillation conditions were further optimized by the orthogonal test Based on the results of the single factor experiments. And the designed experiments and the results are showed on Table 2, the order of the three factors from poor to large was $A>C>B$. The range difference reflects the influence of this factor on the index. At the measured conditions, the degree fragmentation of cinnamomum cassia bark has the most significant impact on distillation performance compared with the solid-liquid ratio and distillation time. The results of the single factor test and orthogonal test indicate that the best process conditions are $\mathrm{A} 2 \mathrm{~B} 2 \mathrm{C} 3$, which is the degree of fragmentation of 40 mesh, the ratio of material to liquid of $1 / 10$ and distillation time $2 \mathrm{~h}$. At these conditions, the extraction rate of cinnamomum cassia oil is $1.44 \%$.

\section{Summary}

In this work, the effects of distillation conditions on extraction performance were investigated to optimize the distillation conditions for extracting cinnamomum cassia oil from cinnamomum cassia bark by steam distillation, including the solid-liquid ratio, distillation time and the fragmentation degree of cinnamomum cassia bark. The experimental results reveal that degree of fragmentation has the most significant effect on the yield of cinnamomum cassia oils, and the optimal distillation conditions are the fragmentation degree of $40 \mathrm{mesh}$, the ratio of material to liquid of $1 / 10$, and the extraction time of $2 \mathrm{~h}$. And the extracted cinnamomum cassia oil is golden yellow and clear. 


\section{Acknowledgement}

The report was prepared within the program supported by Dust-removing Mechanism in Bulk Materials Yard and Development and Application of Wind-proof Dust Suppression Technology Based on Diversion Rectifier(Grand 16-6-2-50-nsh), Development and Application of Wind Dust Suppression Technology Based on Diversion Reactor for Bulk Material Yard (Grand J17KA107) and Creation of Environmentally Friendly Transition Metal Oxide Supported Adsorbents and Their $\mathrm{CO}_{2}$ Capture Behavior (Grand ZR2018BB071).

\section{References}

[1] C. Boutekedjiret, F. Bentahar, R. Belabbes, Extraction of rosemary cinnamomum cassia oil by steam distillation and hydrodistillation, Flavour Fragr. J. 18 (2003), 481-484.

[2] A. Filly, A. Sylvie Fabiano-Tixier, Water as a green solvent combined with different techniques for extraction of cinnamomum cassia oil from lavender flowers, C.R. Chimie. 19 (2016), 707-717.

[3] B.Nabil, A.V.Maryline, A new process for extraction of cinnamomum cassia oil from citrus peels: microwave hydrodiffusion and gravity, J. Food Eng. 90 (2009), 409-413.

[4] M.K.L. Khan, M. Ansar, A. Nazir, A.A. Maan, Sustainable dehydration of onion slices through novel microwave hydro-diffusion gravity technique, Ind. Crop. Prod. Tech. 33 (2016), 327-332.

[5] S.M. Memarzadeh, A.G. Pirbalouti, M. AdibNejad, Chemical composition and yield of cinnamomum cassia oils from bakhtiari savory (Satureja bachtiarica Bunge.) under different extraction methods, Ind. Crop. Pro. 76 (2015), 809-816.

[6] K.A. Hammer, C.F. Carson, T.V. Riley, Antimicrobial activity of cinnamomum cassia oils and other plant extracts, J. Appl. Microbiol. 86 (2010), 985-990.

[7] P. Masango, Cleaner production of cinnamomum cassia oils by steam distillation, J. Clean. Prod. 13 (2005), 833-839.

[8] A. Wesolowska, M. Grzeszczuk, D. Jadczak, Comparison of the chemical composition of cinnamomum cassia oils isolated by water-steam distillation and hydrodistillation from garden thyme (thymus vulgaris L.), J. Essen.Oil Bear. Plan. 19 (2016), 832-842.

[9] L.C. Sotoarmenta, J.C. Sacramentorivero, P.O. Aceretoescoffié, Extraction yield of cinnamomum cassia oil from lippia graveolens leaves by steam distillation at laboratory and pilot scales, J. E.O. P. 20 (2017), 610-621.

[10]M.G. Cerpa, R.B. Mato, M.J. Cocero, Modeling steam distillation of cinnamomum cassia oils: application to lavandin super oil, Accounts. Chem. Res. 54 (2010), 909-917. 